\title{
BMJ Open From QASC to QASCIP: successful Australian translational scale-up and spread of a proven intervention in acute stroke using a prospective pre- test/post-test study design
}

Sandy Middleton, ${ }^{1}$ Anna Lydtin, ${ }^{1}$ Daniel Comerford, ${ }^{2}$ Dominique A Cadilhac, ${ }^{3,4}$ Patrick McElduff, ${ }^{5}$ Simeon Dale, ${ }^{1}$ Kelvin Hill, ${ }^{6}$ Mark Longworth, ${ }^{3}$ Jeanette Ward, ${ }^{7,8}$ $\mathrm{N}$ Wah Cheung, ${ }^{9,10}$ Cate D'Este, ${ }^{11}$ on behalf of the QASCIP Working Group and Steering Committee

To cite: Middleton S, Lydtin A, Comerford D, et al. From QASC to QASCIP: successful Australian translational scale-up and spread of a proven intervention in acute stroke using a prospective pre-test/ post-test study design. BMJ Open 2016;6:e011568 doi:10.1136/bmjopen-2016011568

- Prepublication history for this paper is available online. To view these files please visit the journal online (http://dx.doi.org/10.1136/ bmjopen-2016-011568).

Received 18 February 2016 Accepted 4 March 2016

CrossMark

For numbered affiliations see end of article.

Correspondence to Professor Sandy Middleton; sandy.middleton@acu.edu.au

\section{ABSTRACT}

Objectives: To embed an evidence-based intervention to manage FEver, hyperglycaemia (Sugar) and Swallowing (the FeSS protocols) in stroke, previously demonstrated in the Quality in Acute Stroke Care (QASC) trial to decrease 90-day death and dependency, into all stroke services in New South Wales (NSW), Australia's most populous state.

Design: Pre-test/post-test prospective study.

Setting: 36 NSW stroke services.

Methods: Our clinical translational initiative, the QASC Implementation Project (QASCIP), targeted stroke services to embed 3 nurse-led clinical protocols (the FeSS protocols) into routine practice. Clinical champions attended a 1-day multidisciplinary training workshop and received standardised educational resources and ongoing support. Using the National Stroke Foundation audit collection tool and processes, patient data from retrospective medical record self-reported audits for 40 consecutive patients with stroke per site pre-QASCIP (1 July 2012 to 31 December 2012) were compared with prospective self-reported data from 40 consecutive patients with stroke per site post-QASCIP (1 November 2013 to 28 February 2014). Inter-rater reliability was substantial for 10 of 12 variables.

Primary outcome measures: Proportion of patients receiving care according to the FeSS protocols pre-QASCIP to post-QASCIP.

Results: All $36(100 \%)$ NSW stroke services participated, nominating 100 site champions who attended our educational workshops. The time from start of intervention to completion of post-QASCIP data collection was 8 months. All $(n=36,100 \%)$ sites provided medical record audit data for 2144 patients $(\mathrm{n}=1062$ pre-QASCIP; $\mathrm{n}=1082$ post-QASCIP). Pre-QASCIP to post-QASCIP, proportions of patients receiving the 3 targeted clinical behaviours increased significantly: management of fever (pre: 69\%; post: $78 \%$; $p=0.003$ ), hyperglycaemia (pre: $23 \%$; post: $34 \%$;
Strengths and limitations of this study

Evidence of successful 'scale-up and spread' of a complex, proven intervention across an entire state within a short 8-month time frame.

- An example of large systems transformation involving multidisciplinary clinicians.

- Collaboration between researchers who conducted the original trial, clinicians and quality improvement experts.

- Our tight time frame may not have allowed enough time for full protocol implementation, as some barriers (eg, treatment of hyperglycaemia with insulin) require further attention.

- Use of self-reported processes of care audit data.

$p=0.0085$ ) and swallowing (pre: $42 \%$; post: $51 \%$; $p=0.033$ ).

Conclusions: We obtained unprecedented statewide scale-up and spread to all NSW stroke services of a nurse-led intervention previously proven to improve long-term patient outcomes. As clinical leaders search for strategies to improve quality of care, our initiative is replicable and feasible in other acute care settings.

\section{BACKGROUND}

Implementation science has emerged as a rigorous field of enquiry aiming to generate better evidence about efforts to embed clinical evidence into routine healthcare practice. ${ }^{1}$ Since it can take an average of 17 years for implementation of evidence into standard practice, ${ }^{2}$ evidence to inform selection of strategies is sorely needed to accelerate the pace towards evidence-based practice in a more predictable manner. The Cochrane Effective Practice and Organisation of Care 
(EPOC) group has conducted systematic reviews of interventions aiming to improve knowledge translation. ${ }^{1} 34$ Active, targeted implementation strategies have been shown to be effective in closing evidence-practice gaps and changing clinician behaviour. However, no single implementation strategy is effective in all circumstances for all healthcare settings. ${ }^{1}$ Further research is required into effective models of care $;^{56}$ in addition, the context and barriers to practice change known to influence the success of intervention implementation should be addressed effectively. ${ }^{1}$

One of the difficulties in achieving rapid uptake is that evidence generated from clinical trials is difficult to implement more widely, often due to lack of published details about precisely how the trial was conducted ${ }^{7}$ and a lack of process evaluation, in particular for complex interventions. ${ }^{8} 9$ 'Scalability' of interventions to promote evidence-based practice in healthcare is worthy of greater scientific study. 'Scalability' is 'the ability of a health intervention shown to be efficacious on a small scale and or under controlled conditions to be expanded under real-world conditions to reach a greater proportion of the eligible population, while retaining effectiveness'. ${ }^{10}$ There are relatively few examples in the published literature where efforts to 'scale-up and spread' beyond elite academic centres have been systematically studied. ${ }^{10}$ Those that have been published have focused predominantly on population health initiatives such as mass immunisation programmes. ${ }^{11}{ }^{12}$ Identification of these studies from the literature also is difficult due to the lack of an agreed taxonomy to classify and systematically report them. Furthermore, scalability is often limited by insufficient detail by researchers of the 'nuts and bolts' of a successful intervention. ${ }^{13}$

One example of a large-scale intervention involving scale-up and spread in the acute care setting is the Michigan Keystone project. ${ }^{14}$ This cohort study demonstrated improvements in rates of central venous catheter bloodstream infections in 103 intensive care units (ICUs) in the USA following introduction of a checklist of five evidence-based practices for management of central venous catheters, implemented using clinical champions, education and coaching. Simultaneously, ICUs implemented daily goal sheets to improve communication, an intervention to reduce ventilator-assisted pneumonia and a programme to improve the safety culture. Elements of the project subsequently were adapted and introduced into 200 ICU settings in the UK in the Matching Michigan study. ${ }^{15}$ While central venous catheter bloodstream infections dropped in the UK ICUs, the Matching Michigan study was not an exact replica of the original Michigan Keystone project, particularly in terms of implementation of the intervention. ${ }^{16}$

As reported elsewhere, ${ }^{17}$ our team previously developed a successful implementation intervention that aligned clinical practice in participating stroke units more directly with the evidence. This complex healthcare intervention resulted in significant improvements in patient outcomes. In brief, our Quality in Acute Stroke Care (QASC) trial showed that a multidisciplinary, nurse-initiated intervention focused on three clinical protocols to manage FEver, hyperglycaemia (Sugar) and Swallowing dysfunction (the FeSS protocols; box 1) in the first $72 \mathrm{~h}$ of patient admission significantly decreased death and disability by $16 \%(p=0.002)$. These dramatic improvements in death and dependency were larger than any pharmacological ${ }^{18}$ or organisational ${ }^{19}$ initiatives for acute stroke known at that time. To design that intervention, we had incorporated best practice from the field of implementation science to design a standardised intervention comprising systematic local barrier identification, ${ }^{20}$ reinforcement of multidisciplinary teamwork, ${ }^{21}$ local adaptation ${ }^{22}$ and use of site champions. ${ }^{23}$ This cluster randomised controlled trial also showed that this intervention changed process of care as well as patient outcomes by significantly reducing fever, glucose levels and improved swallow screening practices. ${ }^{24}$

Our next challenge as a team of clinicians, academics and health service managers was how to 'scale-up and spread' this effective intervention beyond original trial sites to reach all hospitals in New South Wales (NSW), the most populous Australian jurisdiction. We did not want to leave the uptake of this intervention to chance. Instead, we aimed to test our success in scaling up these three clinical protocols to all 36 NSW stroke services using those intervention elements demonstrated to be effective in the QASC trial. Known as the QASC Implementation Project (QASCIP), this statewide scale-up of our proven intervention was evaluated rigorously by measuring impact on clinical care for fever, hyperglycaemia and swallowing dysfunction

Box 1 Summarised elements of the Fever, Hyperglycaemia (Sugar) Swallowing (FeSS) clinical protocols used in the Quality in Acute Stroke Care (QASC) Implementation Project (QASCIP)

Fever

- Temperature readings 4-6 hourly for the first $72 \mathrm{~h}$

- If temperature $>37.5^{\circ} \mathrm{C}$, treat with paracetamol

- Sugar (hyperglycaemia)

- Formal venous glucose on admission to the emergency department or stroke service

- Blood sugar readings 4-6 hourly for the first $72 \mathrm{~h}$ for people with known diabetes

- Blood sugar readings 4-6 hourly for the first $48 \mathrm{~h}$ for people not known to have diabetes

- If glucose $>10 \mathrm{mmol} / \mathrm{L}$, treat with insulin

Swallowing

- Swallow screen or swallow assessment within $24 \mathrm{~h}$ of admission and prior to being given oral food, drink or medications

- Referral to speech pathologist for full assessment for those who fail the swallow screen 
management as described below. We report the findings based on the SQUIRE (Standards for Quality Improvement Reporting Excellence) guidelines. ${ }^{25}$

\section{METHODS}

All NSW stroke services $(n=36)$ were invited to participate in this prospective pre-test/post-test study: these comprised 31 sites with dedicated stroke units in large hospitals and five sites without dedicated stroke units but with integrated hospital stroke services based on agreed hospital service delineations. ${ }^{26}$ Those sites which had previously participated in the QASC trial were also eligible to participate (irrespective of whether they had been allocated to the intervention or control group).

A personal invitation letter and study summary were sent to senior clinical and management executives in each stroke service including chief executives of the respective local health district; clinical directors of all 36 stroke services; directors of nursing; directors of allied health; stroke clinical nurse consultants/coordinators and, where applicable, stroke service/stroke unit nurse unit managers. In our invitation, sites were asked to consent to nominate up to three clinical stroke champions to act as local change agents for 'scale-up and spread' of the intervention. Our study then faithfully replicated the intervention from the QASC trial as described below (box 2).

\section{Scale-up and spread initiative}

Clinical champions from each participating hospital attended a 1-day educational workshop where education and training were provided about: (1) the FeSS protocols, including ASSIST swallow screening training (see below); (2) barrier and enabler identification; and (3) reinforcement of multidisciplinary teamwork. A small change to the Sugar protocol used in the QASC trial was made whereby the treatment point for raised glucose was lowered from 11 to $10 \mathrm{mmol} / \mathrm{L}$ to align with the newly released Australian Diabetes Society Guidelines for Routine Glucose Control in Hospital. ${ }^{27}$ The ASSIST swallow screening training package consisted of online

Box 2 Summarised elements of the implementation strategy used in the Quality in Acute Stroke Care (QASC) Implementation Project (QASCIP)

The QASCIP implementation intervention consisted of:

- Informing Local Health District (LHD) chief executives and key health service managers

- Engaging multidisciplinary clinicians and clinical champions at each participating hospital

- A 1-day multidisciplinary training workshop for clinical champions in order to assess barriers and enablers, provide education and reinforce teamwork

- Interactive educational meetings and provision of educational resources

Support in the form of site visits, telephone and email contact education with case scenarios and a knowledge test to train non-speech pathologists (ie, nurses and medical staff) to competently perform a swallow screen for patients with acute stroke. Patients who failed the swallow screen were to be kept nil by mouth and referred to a speech pathologist for a swallow assessment. Clinical champions were also provided with implementation tools and educational materials including a prepackaged PowerPoint presentation for use in their sites; a 'barrier and enabler' assessment tool, an implementation plan template, and a suggested implementation and evaluation timeline (all are freely available for download at http://www.acu.edu.au/qasc). The aim of this suite of clinical and educational tools was to facilitate efforts by clinical champions at their own sites to lead implementation in their local stroke services based on an effective intervention.

Clinical champions were charged with targeting all clinicians in their stroke services. They were not obliged to engage their respective emergency department or ICU but rather to concentrate their efforts on changing practice in their stroke service. We allowed 1 month for clinical champions to return to their sites and begin implementation. Prior to the start of the postimplementation audit and consistent with the QASC trial, ${ }^{17}$ we also allowed for an additional 3-month bedding down period to establish the FeSS clinical protocols into routine care. All participating sites were visited by the project coordinator and the NSW Agency for Clinical Innovation (ACI) Stroke Network Manager at least once during this 'bedding down' period. The project coordinator provided monthly proactive and reactive ongoing support to the clinical champions via email and telephone.

\section{Retrospective medical audit pre-QASCIP}

To establish pre-QASCIP practice, following consent from stroke services, the National Stroke Foundation (NSF) provided the researchers with self-reported data previously collected independently of our study as part of the NSF National Clinical Audit (using patient data for stroke admissions between 1 July 2012 and 31 December 2012) ${ }^{28}$ and the NSF Organisational Survey (data collected 1 April to 31 May 2013). ${ }^{29}$ Using the established NSF audit web-based tool, ${ }^{30}$ clinical champions had conducted this retrospective audit of the records for the first 40 consecutive patients with a primary diagnosis of stroke admitted to the stroke unit between 1 July 2012 and 31 December 2012, excluding patients with subarachnoid haemorrhage, subdural and extradural haematoma, and transient ischaemic attacks. Any sites which had not participated in either of these previous NSF audits provided self-reported retrospective preintervention data directly to the researchers using the NSF web-based audit tool in an identical manner and time period.

All clinical champions received training at the QASCIP workshop on the auditing process. In addition, 
online audit training was made available to the site auditors through the NSF website with monthly support teleconferences.

\section{Instrument}

For the preimplementation and postimplementation audit, we used 19 existing relevant items from the 2013 NSF Clinical Audit as follows: fever: $n=4$; hyperglycaemia: $\mathrm{n}=5$; swallowing: $\mathrm{n}=4$ and patient demographics: $\mathrm{n}=6$. As collected through the NSF National Clinical Audit, these questions assessed frequency of temperature and glucose monitoring and treatment for the first $72 \mathrm{~h}$ after stroke admission. The swallowing questions examined the time and date the swallow screen was completed, if patients were kept nil by mouth before a screen and prior to food, fluids or oral medications, and if patients were kept nil by mouth after a failed screen and subsequent referral to a speech pathologist. In addition, we also accessed eight existing relevant items from the 2013 NSF Organisation Survey regarding existing hospital and stroke service characteristics, namely location (metropolitan/rural); presence of dedicated stroke unit (yes/no); regular multidisciplinary team meetings (yes/no); whether there were existing clinical care pathways for: stroke, fever management, hyperglycaemia management, swallowing management (yes/no for each); and current use of the ASSIST swallowing screening tool (yes/no).

\section{Prospective medical audits post-QASCIP}

Participating sites were also required to conduct a selfreported prospective audit for the first 40 consecutive patients from the postimplementation period, namely 1 November 2013 to 28 February 2014, using identical NSF tools and equivalent inclusion criteria. The postimplementation audits were started 4 months after the one-day educational workshop, with a total of 8 months between this workshop and completion of the postimplementation audits.

Using the postimplementation cohort, inter-rater reliability was undertaken through repeat medical record audits for four key outcome measures for fever, five for hyperglycaemia and three for swallowing dysfunction at each site using different auditors as per the standard NSF data collection method to measure data reliability. ${ }^{28}$ Stroke services were asked to reaudit the first five consecutive patients; however, those stroke services with a lower volume of patients with stroke $(<20$ in the postimplementation cohort) were only required to reaudit records for three patients.

\section{Data analysis}

De-identified data were analysed by an independent statistician. Aboriginality, age group, sex, history of diabetes and premorbid modified Rankin Score (mRS) were compared between patients included in the preimplementation and postimplementation audits using a logistic regression model, and length of stay was compared between the precohorts and postcohorts using a linear model; these models included pre-post as the explanatory variable and used a generalised estimating equations (GEEs) approach to adjust for correlation of observations within hospitals.

The number and proportion of patients with each of the monitoring and treatment elements for all three of the FeSS protocols were compared between the preimplementation and postimplementation periods. In addition, we calculated overall monitoring adherence, overall treatment adherence and a composite measure of appropriate monitoring and treatment for all three of the FeSS protocols.

To compare monitoring and treatment outcomes from preimplementation to postimplementation, logistic regression analyses were undertaken, which included audit period (preimplementation or postimplementation) as the primary predictor variable of interest. The logistic regression models were fit within a GEEs framework to adjust for correlation of patients within hospitals. ORs and 95\% CIs are presented for the key composite outcomes of appropriate monitoring and treatment for each of the three FeSS protocols.

For each of the preintervention FeSS monitoring and treatment practices, we also report the corresponding proportion for the post-QASC trial findings from the 10 QASC trial intervention sites; however, small sample sizes in the audit precluded significance testing.

We also examined associations between change in adherence to the three clinical protocols from preimplementation to postimplementation and the following factors: (1) volume of stroke admissions $(<100$ vs $\geq 100$ patients with stroke/year); (2) hospitals with a dedicated stroke unit and hospitals with a stroke service; (3) hospitals that participated in the original QASC trial and hospitals that only participated in the QASCIP; (4) hospitals randomised to the original QASC trial intervention group and hospitals that only participated in the QASCIP; and (5) hospital location (rural (population $<25000$ ) vs urban (population $\geq 25000)$ ). We generated a separate model for each of the five factors which included time (preimplementation/postimplementation), the factor of interest and the interaction between these two variables. The $p$ values for the interaction term was used to determine whether the factor was associated with change in protocol adherence.

Patients admitted for $<24 \mathrm{~h}$ were excluded from all analyses as outcomes were assessed in $24 \mathrm{~h}$ blocks of time. In addition, where patients were only admitted for $48 \mathrm{~h}$, observations for days 1 and 2, but not day 3, were included in the analyses. Patients not known to have diabetes, with no episode of hyperglycaemia (blood glucose level (BGL) $>10 \mathrm{mmol} / \mathrm{L}$ ) in the first $48 \mathrm{~h}$, were excluded from the monitoring element $4-\mathrm{M} 4$ in the analysis as per the clinical protocol. Data recorded as 'not documented' and 'unknown' were assumed to be negative and included in the relevant denominator.

$\kappa$ Values with $95 \%$ CIs were calculated to determine the inter-rater reliability. 
Adherence to clinical audit standards

Adherence to 29 of the 30 relevant standards from the then proposed UK standards for design and conduct of a national clinical audit or quality improvement study was also documented. ${ }^{31}$

\section{RESULTS}

\section{Service characteristics}

All 36 stroke service sites agreed to participate. All 32 sites who had participated in the routine $2013 \mathrm{NSF}$ Clinical Audit data consented to the QASCIP researchers having access to their precollected hospital NSF audit data. The remaining four stroke services provided data directly to the researchers. In addition, consent was provided by the majority of participating sites $(n=35)$ to access data from the routine 2013 NSF Organisational Survey to provide hospital characteristics data. The one site that had not participated in the 2013 NSF Organisational Survey provided hospital characteristics directly to the project team.

Most hospitals participating in the study had a dedicated stroke unit $(n=31,86 \%)$; most were located in the metropolitan region $(n=32,89 \%)$. Those self-reporting already having existing protocols were as follows: management of fever $(n=32,89 \%)$, hyperglycaemia $(n=30$, $83 \%)$, swallowing $(\mathrm{n}=35,97 \%)$ and having a clinical care pathway for stroke ( $\mathrm{n}=32,92 \%$; table 1$)$.

\section{Pre-QASCIP and post-QASCIP audit results}

We obtained data for 1062 patients treated in the preintervention period and 1082 patients in the postintervention period (some hospitals did not have 40 stroke admissions during the audit periods). There were no significant differences between patients in the preimplementation and postimplementation cohorts in terms of aboriginality $(p=0.09)$, age group $(p=0.15)$, gender $(\mathrm{p}=0.88)$, diabetes status $(\mathrm{p}=0.24)$ and premorbid $\mathrm{mRS}$ ( $\mathrm{p}=0.89$; table 2$)$.

Length of stay data were available for 901 patients in the preimplementation audit and 857 in the postimplementation audit. Length of stay was similar for the preimplementation cohort (median 6.0 days; minimum 1.0, maximum 76 days) and for the postimplementation cohort (median 5.0 days; minimum 1.0, maximum 53 days; $p$ from the GEE linear model $=0.18$ ).

Significantly increased proportions of patients received care according to the fever protocol from preimplementation to postimplementation (pre: 69\%; post: $78 \%$; $=0.003$; OR $1.6,95 \%$ CI 1.2 to 2.2 ). Specifically, significantly higher proportions of patients postimplementation were monitored for fever on days 1-3. However, of the 135 patients with a febrile episode in the postimplementation cohort, only $64(47 \%)$ received paracetamol within $1 \mathrm{~h}$, a non-statistically significant increase from preimplementation (38\%; table 3$)$.

There were significantly increased proportions of patients who received care according to the hyperglycaemia (sugar) protocol from preimplementation to postimplementation (pre: 23\%; post: $34 \%$; $\mathrm{p}=0.0085$; OR $1.8,95 \%$ CI 1.2 to 2.7 ). Specifically, significantly increased proportions of patients from preimplementation to postimplementation had their BGL monitored on days 1-3. However, of the 205 patients in the postimplementation cohort who had a finger-prick glucose level $>10 \mathrm{mmol} / \mathrm{L}$, only $56(27 \%)$ received insulin within the $1 \mathrm{~h}$ recommended time interval, with no clinical or statistically significant improvement from preimplementation (22\%; table 4).

The proportion of patients receiving care according to the swallowing protocol increased from preimplementation to postimplementation (pre: 42\%; post: 51\%; $\mathrm{p}=0.033)$. Specifically, increased proportions of patients with acute stroke received a swallow screen or swallow assessment within $24 \mathrm{~h}$, and prior to receiving oral food or drink or medications. Similar high proportions of patients, preimplementation $(97 \%)$ and postimplementation $(95 \%)$, who failed a swallow screen subsequently received a swallow assessment by a speech pathologist as recommended (table 5).

Of note, statewide overall monitoring and treatment practices preimplementation were higher when

\section{Table 1 Hospital characteristics}

\begin{tabular}{|c|c|}
\hline & $\begin{array}{l}\text { Total hospitals } \\
\text { in study } \\
(n=36)\end{array}$ \\
\hline \multicolumn{2}{|l|}{ Hospital location } \\
\hline Metropolitan & $32(89 \%)$ \\
\hline Rural & $4(11 \%)$ \\
\hline Hospitals with a dedicated stroke unit & $31(86 \%)$ \\
\hline Hospitals with a clinical care pathway for managing stroke & $33(92 \%)$ \\
\hline Hospitals with regular stroke multidisciplinary team meetings & $34(94 \%)$ \\
\hline Hospitals with an agreed management (including assessment and monitoring) protocol for fever & $32(89 \%)$ \\
\hline Hospitals with an agreed management (including assessment and monitoring) protocol for hyperglycaemia & $30(83 \%)$ \\
\hline Hospitals with an agreed management (including assessment and monitoring) protocol for swallow & $35(97 \%)$ \\
\hline Hospitals that use the ASSIST tool & $28(78 \%)$ \\
\hline
\end{tabular}


Table 2 Patient demographics

\begin{tabular}{|c|c|c|c|c|}
\hline & \multicolumn{3}{|l|}{ Statewide aggregate } & \multirow{2}{*}{$\begin{array}{l}\text { QASC trial } \\
\text { Intervention } \\
\text { hospitals } \\
(\mathrm{n}=603)\end{array}$} \\
\hline & $\begin{array}{l}\text { Preimplementation } \\
\text { audit } \\
(n=1062)\end{array}$ & $\begin{array}{l}\text { Postimplementation } \\
\text { audit } \\
(n=1082)\end{array}$ & p Value & \\
\hline \multicolumn{5}{|c|}{ Aboriginal or Torres Strait Islander } \\
\hline Yes & $33(3.1 \%)$ & $23(2.1 \%)$ & 0.09 & $5(0.8 \%)$ \\
\hline No & $983(93 \%)$ & $1034(96 \%)$ & & $506(84 \%)$ \\
\hline Refused/Don’t know & $46(4.3 \%)$ & $25(2.3 \%)$ & & $92(15 \%)$ \\
\hline \multicolumn{5}{|l|}{ Age group } \\
\hline$<65$ & $264(25 \%)$ & $241(22 \%)$ & 0.15 & $197(33 \%)$ \\
\hline 65 to 74 & $252(24 \%)$ & $252(23 \%)$ & & $141(23 \%)$ \\
\hline 75 to 84 & 350 (33\%) & 350 (33\%) & & $171(28 \%)$ \\
\hline Over 85 & $193(18 \%)$ & $232(22 \%)$ & & $94(16 \%)$ \\
\hline \multicolumn{5}{|l|}{ Gender } \\
\hline Male & $589(55 \%)$ & $599(55 \%)$ & 0.88 & $358(60 \%)$ \\
\hline \multicolumn{5}{|l|}{ Diabetes } \\
\hline Yes & $271(26 \%)$ & $254(23 \%)$ & 0.24 & $108(18 \%)$ \\
\hline \multicolumn{5}{|c|}{ Premorbid mRS (prior to admission to hospital) } \\
\hline $\begin{array}{l}0 \text { or } 1 \text { (None or minimal } \\
\text { disability) }\end{array}$ & $672(66 \%)$ & $692(66 \%)$ & 0.89 & $476(93 \%)$ \\
\hline
\end{tabular}

compared with data collected from the 10 intervention hospitals at conclusion of the original QASC trial which had been completed some 24 months earlier, for example, monitoring adherence for fever (QASCIP preimplementation: 69\% vs QASC trial: 44\%); hyperglycaemia (QASCIP preimplementation: 23\% vs QASC trial: $3.5 \%$ ) and swallowing (QASCIP preimplementation: $42 \%$ vs QASC trial: $10 \%$ ).

There were no significant differences in change in whether patients were monitored and treated according to the protocol from preimplementation to postimplementation and number of stroke admissions $(<100$ vs $\geq 100$ patients with stroke/year $)$ for fever $(p=0.75)$, hyperglycaemia $(p=0.95)$ and swallowing $(p=0.28)$. Similarly, there were no significant differences in preimplementation to postimplementation change in adherence between hospitals with a dedicated stroke unit compared with hospitals without (ie, with only a stroke service) for the fever protocol $(\mathrm{p}=0.81)$, the hyperglycaemic protocol $(\mathrm{p}=0.31)$ and the swallowing protocol $(\mathrm{p}=0.09)$.

No significant differences were found between rural and urban hospitals and change in whether patients were monitored and treated according to fever protocol $(p=0.11)$ or the swallowing protocol $(p=0.052)$. There were, however, statistically significant improvements for monitoring and treatment according to the hyperglycaemic protocol in urban sites (preimplementation: $\mathrm{n}=228$ (23\%); postimplementation; $\mathrm{n}=356$ $(35 \%)$ ) when compared with rural sites (preimplementation: $\mathrm{n}=12$ (14\%); postimplementation; $\mathrm{n}=7$ $(11 \% ; \mathrm{p}=0.0006))$.

There were no significant differences between hospitals that participated in the original QASC trial and hospitals that only participated in the QASCIP in pre-post change in monitoring and treatment adherence to: the fever protocol $(\mathrm{p}=0.48)$, the hyperglycaemic protocol $(\mathrm{p}=0.85)$ and the swallowing protocol $(\mathrm{p}=0.57)$. Likewise, there was no difference between hospitals randomised to the original QASC trial intervention group and hospitals that only participated in the QASCIP and change from preimplementation to postimplementation in whether patients were monitored and treated according to the fever protocol $(p=0.54)$ or the swallowing protocol $(p=0.77)$. However, adherence to the hyperglycaemic protocol in those hospitals which received the QASC intervention in the original trial remained consistent from preimplementation $(37 \%)$ to postimplementation $(35 \%)$, but increased from preimplementation (16\%) to postimplementation $(33 \%)$ for the hospitals which did not receive the QASC intervention as part of the original trial $(\mathrm{p}=0.02)$.

Inter-rater reliability data were provided for a total of 148/1082 (14\%) postimplementation patients from all participating hospitals. For 10 of the 12 patient variables in the postimplementation clinical audit, the $\kappa$ values indicated substantial inter-rater reliability (ie, >0.6; figure 1). ${ }^{32}$

\section{Adherence to audit standards}

Of the 30 proposed UK standards for design and conduct of a national clinical audit or quality improvement study, 29 standards were relevant to our audit. One standard was not applicable as our audit did not involve any electronic data linkage. We adhered to 29 of the 29 $(100 \%)$ proposed standards for the design and conduct of a national clinical audit or quality improvement study relevant to our context. 
Table 3 Number and proportion of patients monitored and treated according to fever protocol

\begin{tabular}{|c|c|c|c|c|c|c|}
\hline \multirow[b]{2}{*}{ Element } & \multirow[b]{2}{*}{ Monitoring and treatment for fever } & \multicolumn{4}{|l|}{ Statewide aggregate } & \multirow{2}{*}{$\begin{array}{l}\text { QASC trial } \\
\text { Intervention } \\
\text { group } \\
(n=603)\end{array}$} \\
\hline & & $\begin{array}{l}\text { Preimplementation } \\
\text { audit } \\
(\mathrm{n}=1062)\end{array}$ & $\begin{array}{l}\text { Postimplementation } \\
\text { audit } \\
(n=1082)\end{array}$ & OR $(95 \% \mathrm{Cl})$ & p Value & \\
\hline & Monitoring & & & & & \\
\hline M1 & Temperature recorded at least four times on day 1 & $924(87 \%)$ & 1025 (95\%) & 2.68 (1.60 to 4.50$)$ & 0.0002 & $545(93 \%)$ \\
\hline M2 & Temperature recorded at least four times on day 2 & $861(84 \%)$ & $940(91 \%)$ & $1.89(1.30$ to 2.76$)$ & 0.0009 & $482(82 \%)$ \\
\hline \multirow[t]{3}{*}{ M3 } & $\begin{array}{l}\text { Temperature recorded at least four times on day } 3 \\
\text { Monitoring adherence }{ }^{*}\end{array}$ & $764(82 \%)$ & $833(88 \%)$ & 1.56 (1.11 to 2.20$)$ & 0.011 & 379 (64\%) \\
\hline & $\begin{array}{l}\text { Monitored according to protocol for fever } \\
\text { Treatment }\end{array}$ & $802(76 \%)$ & 906 (84\%) & 1.66 (1.18 to 2.34$)$ & 0.0033 & $337(56 \%)$ \\
\hline & At least one febrile event (temperature $\geq 37.5^{\circ} \mathrm{C}$ ) & $149(14 \%)$ & $135(12 \%)$ & $0.89(0.65$ to 1.21$)$ & 0.45 & $105(17 \%)$ \\
\hline \multirow[t]{2}{*}{ T1 } & $\begin{array}{l}\text { Received paracetamol within } 1 \mathrm{~h} \text { of their first febrile event } \\
\text { (temperature } \geq 37.5^{\circ} \mathrm{C} \text { ) } \\
\text { Protocol adherence: monitored and treated }+\end{array}$ & $57(38 \%)$ & $64(47 \%)$ & $1.45(0.95$ to 2.20$)$ & 0.08 & $19(18 \%)$ \\
\hline & Monitored and treated according to the protocol for fever & 729 (69\%) & $845(78 \%)$ & $1.62(1.18$ to 2.24$)$ & 0.0031 & $258(44 \%)$ \\
\hline
\end{tabular}

Day 1 indicates first $24 \mathrm{~h}$ since admission to hospital. The protocol recommends that observations should be taken at least six hourly, so there should be at least four separate temperature recordings during the first $24 \mathrm{~h}$ of admission.

Statistically significant $p$ values are shown in bold.

${ }^{*}$ Must meet all M1, M2 and M3 to be deemed as having been monitored according to protocol.

†Must meet all M1, M2, M3 and T1 to be deemed as having been monitored and treated according to protocol.

QASC, Quality in Acute Stroke Care. 


\begin{tabular}{|c|c|c|c|c|c|c|}
\hline \multirow[b]{2}{*}{ Element } & \multirow[b]{2}{*}{ Monitoring and treatment } & \multicolumn{4}{|l|}{ Statewide aggregate } & \multirow{2}{*}{$\begin{array}{l}\text { QASC trial } \\
\text { Interventio } \\
\text { n group } \\
(n=603) \\
\end{array}$} \\
\hline & & $\begin{array}{l}\text { Preimplementation } \\
\text { audit } \\
(\mathrm{n}=1062)\end{array}$ & $\begin{array}{l}\text { Postimplementation } \\
\text { audit } \\
(\mathrm{n}=1082)\end{array}$ & OR $(95 \% \mathrm{Cl})$ & p Value & \\
\hline & Monitoring & & & & & \\
\hline M1 & Formal VBG measurement in the ED & $678(64 \%)$ & $754(70 \%)$ & $1.28(0.83$ to 1.97$)$ & 0.27 & $184(31 \%)$ \\
\hline M2 & $\begin{array}{l}\text { Finger-prick blood glucose level recorded at least four } \\
\text { times on day } 1\end{array}$ & $533(50 \%)$ & $749(69 \%)$ & 2.50 (1.66 to 3.75$)$ & $<0.0001$ & $362(60 \%)$ \\
\hline M3 & $\begin{array}{l}\text { Finger-prick blood glucose level recorded at least four } \\
\text { times on day } 2\end{array}$ & $442(43 \%)$ & $679(66 \%)$ & 2.81 (1.89 to 4.16$)$ & $<0.0001$ & $314(52 \%)$ \\
\hline M4 & $\begin{array}{l}\text { Finger-prick blood glucose level recorded at least four } \\
\text { times on day } 3 \\
\text { Monitoring adherence }\end{array}$ & $179(60 \%)$ & $222(79 \%)$ & 2.41 (1.54 to 3.78$)$ & 0.0001 & $311(52 \%)$ \\
\hline \multirow{5}{*}{ T1 } & $\begin{array}{l}\text { Monitored according to the protocol for hyperglycaemia } \\
\text { Treatment }\end{array}$ & $301(28 \%)$ & $424(39 \%)$ & $1.66(1.11$ to 2.48$)$ & 0.014 & $61(10 \%)$ \\
\hline & At least one finger-prick glucose level of $>10 \mathrm{mmol} / \mathrm{L}$ & $187(18 \%)$ & 205 (19\%) & 1.11 (0.85 to 1.43$)$ & 0.44 & $135(22 \%)$ \\
\hline & $\begin{array}{l}\text { Insulin received within } 1 \mathrm{~h} \text { of their finger-prick glucose } \\
\text { level of }>10 \mathrm{mmol} / \mathrm{L}\end{array}$ & $41(22 \%)$ & $56(27 \%)$ & $1.32(0.79$ to 2.21$)$ & 0.30 & $19(14 \%)$ \\
\hline & Protocol adherence: monitored and treated & & & & & \\
\hline & $\begin{array}{l}\text { Monitored and treated according to the protocol for } \\
\text { hyperglycaemia }\end{array}$ & $240(23 \%)$ & $363(34 \%)$ & $1.76(1.16$ to 2.69$)$ & 0.0085 & $21(3.5 \%)$ \\
\hline $\begin{array}{l}\text { Day } 1 \text { indic } \\
\text { blood gluc } \\
\text { Statistically } \\
\text { *Must mee } \\
\text { more episc } \\
\text { monitored } \\
\text { †Must mee } \\
\text { ED, emerg }\end{array}$ & 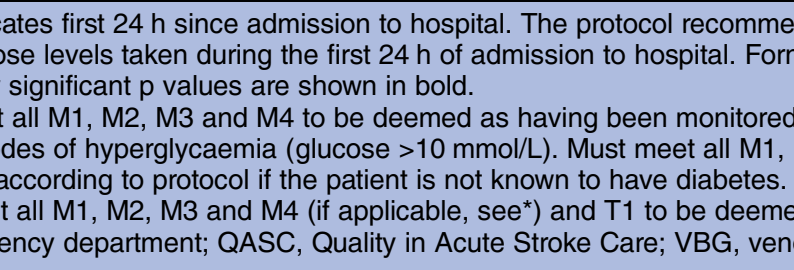 & $\begin{array}{l}\text { servations should be take } \\
\text { fined as: blood glucose sa } \\
\text { to protocol if the patient is } \\
\text { and have no episode of } r \\
g \text { been monitored and trea } \\
\text { lucose. }\end{array}$ & $\begin{array}{l}\text { hat least six hourly, so ther } \\
\text { ample sent to laboratory for } \\
\text { known to have diabetes or } \\
\text { yperglycaemia (glucose }>10 \\
\text { ted according to protocol. }\end{array}$ & $\begin{array}{l}\text { e should be at least fou } \\
\text { analysis. } \\
\text { is not known to have di } \\
0 \mathrm{mmol} / \mathrm{L} \text { ) to be deemed }\end{array}$ & $\begin{array}{l}\text { r separate fir } \\
\text { abetes but } h \\
\text { l as having b }\end{array}$ & $\begin{array}{l}\text { ger-prick } \\
\text { as one or } \\
\text { een }\end{array}$ \\
\hline
\end{tabular}

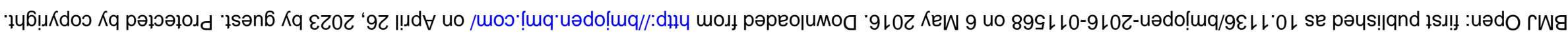


Table 5 Number and proportion of patients monitored and treated according to swallowing protocol

Statewide aggregate

Preimplementation

audit

Element Monitoring and treatment for swallowing

$(n=1062)$

audit

QASC trial

Monitoring

Received a swallow screen within $24 \mathrm{~h}$ of admission to hospital

$453(43 \%)$

Received a swallow assessment within $24 \mathrm{~h}$ of hospital admission $404(38 \%)$

$733(69 \%)$

$(n=1082)$

$605(57 \%)$

$562(52 \%)$

$418(39 \%)$

$814(75 \%)$

of hospital admission

M2

Received a swallow screen or a swallow assessment before they

were given food or drink (orally)

M3 Received a swallow screen or a swallow assessment before they

were given oral medications

Monitoring adherence*

Monitored according to protocol for swallow dysfunction

$550(52 \%)$

$736(68 \%)$

$670(62 \%)$

$454(43 \%)$

$565(52 \%)$

$178(17 \%)$

$230(21 \%)$

$218(95 \%)$

Intervention

Treatment

Failed the swallow screen

$173(97 \%)$

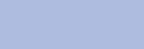

Protocol adherence: monitored and treated

Monitored and treated according to the protocol for swallowing

$450(42 \%)$

$556(51 \%)$

OR $(95 \% \mathrm{Cl})$

p Value

group

$(n=603)$ dysfunction

$1.57(1.15$ to 2.15$) \quad 0.0047$

$284(47 \%)$

1.01 (0.84 to 1.22$) \quad 0.91$

$\begin{array}{lll}1.01(0.84 \text { to } 1.22) & 0.91 & 330(55 \%) \\ 1.38(1.09 \text { to } 1.74 & \mathbf{0 . 0 0 6 8} & 491(81 \%)\end{array}$

Day 1 indicates first $24 \mathrm{~h}$ since admission to hospital
Statistically significant $\mathrm{p}$ values are shown in bold.

Statistically significant $\mathrm{p}$ values are shown in bold.

${ }^{*}$ Must meet all M1, M2 and M3 to be deemed as having been monitored according to protocol.

†Must meet all M1, M2, M3 and T1 to be deemed as having been monitored and treated according to protocol.

QASC, Quality in Acute Stroke Care. 
Figure 1 Inter-rater reliability for 12 key individual variables.

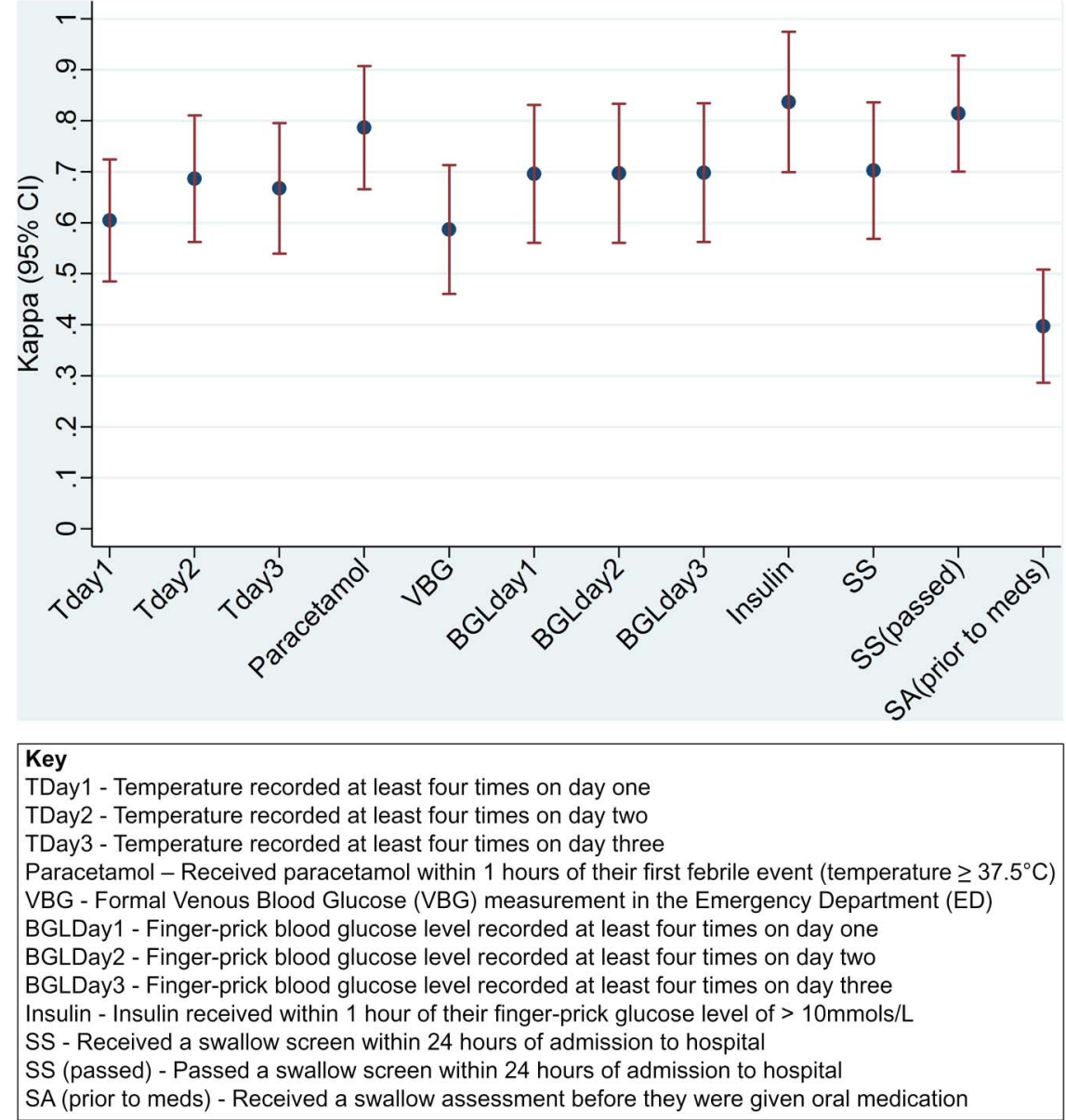

\section{DISCUSSION}

The reporting of 'scale-up' at the national or state level of an implementation intervention proven effective in changing clinical practice and improving patient outcomes is limited. There is a pressing need for highquality studies to assess mechanisms by which interventions, shown to be effective in academic centres or hospitals inclined to participate in health services research, can be 'scaled up' to every relevant clinical setting. ${ }^{33}$

This is one of the few studies to examine a systematic effort to 'scale-up and spread' an effective implementation strategy in acute healthcare. Furthermore, the pace and geographical scale-up and spread were notable. Since successful evidence translation can take decades, ${ }^{2}$ the fact we achieved these significant and clinically important changes within a short 8-month time frame, only 4 years since publication of our original trial, and in all stroke services across an entire state, is laudable. Having tested resources and tools available from the QASC trial, combined with evidence from the rigorous process evaluation, ${ }^{24}$ enabled the rapid replication in the real world and reduced the evidence-to-practice translation timeline by many years.

Our implementation study demonstrated significant improvements in adherence to all three FeSS clinical protocols. Having proven the effectiveness of implementation strategies in the earlier QASC trial provided an incontrovertible foundation for QASCIP itself. Additional strengths of QASCIP included $100 \%$ participation of all NSW stroke services. That this study embraced smaller stroke services as well as hospitals with dedicated stroke units was also noteworthy.

The significant improvement in monitoring for all three elements was encouraging, with the exception of formal venous blood glucose measurement, which warrants further attention. Routine collection of this measure is potentially achievable through the embedding of serum glucose in electronic pathology orders for patients with stroke on admission to the emergency department. However, although treatment practices did not significantly improve for fever (administration of paracetamol), the number of patients with fever was small.

Use of insulin for hyperglycaemia remained poor with less than a third of patients who required insulin not receiving it. As in the QASC trial, QASCIP did not supply insulin administration protocols to sites. This was a deliberate and pragmatic approach as new treatment protocols of this nature require extensive local consultation and time to implement and it was decided that hospitals would use their locally agreed current inpatient protocols while adhering to the principles of best 
practice for glucose management. Anecdotal evidence gathered at the site support visits highlighted that not all hospitals had an agreed inpatient insulin administration protocol for management of hyperglycaemia and that these sites may have benefited by provision of such insulin administration guidelines which may then have improved adherence.

Swallowing surveillance in the form of a swallowing screen by a non-speech pathologist or a swallowing assessment by a speech pathologist within $24 \mathrm{~h}$ was also less than optimal even in the postimplementation cohort $(75 \%)$. This requires further attention. Patients continue to be fed and given oral medications prior to a swallow screen or assessment. In contrast, the percentage of patients who failed the swallowing screen and correctly received a swallowing assessment by a speech pathologist was encouragingly high preimplementation $(97 \%)$, remaining so postimplementation (95\%).

Of note, the majority of sites reported already having fever, hyperglycaemia and swallowing management practices and protocols prior to participation in the study. Acknowledging that these protocols may have varied somewhat from the FeSS clinical protocols, higher preimplementation adherence rates might reasonably have been expected.

Of interest, preimplementation practices for the protocol adherence (ie, monitoring and treatment practices) for fever, hyperglycaemia and swallowing across the state were already higher in comparison to postimplementation data collected from the 10 intervention hospitals in the original QASC trial. This improvement over time was also reflected in national data from the 2013 NSF audit (fever: monitoring adherence $71 \%$, paracetamol within an hour $36 \%$; hyperglycaemia: monitoring adherence $18 \%$, insulin treatment $25 \%$; swallowing: monitoring adherence $39 \%$ (no swallowing treatment data available)) ${ }^{34}$ We speculate that this could potentially be due to widespread publicity, media reporting and dissemination at conferences and seminars of the results of the original QASC trial following its publication in the Lancet in 2011, that is, passive dissemination. The significant improvement from pre-to-post for those QASCIP hospitals which did not receive the intervention as part of the original QASC trial was potentially due to lower adherence preimplementation for the non-QASC trial intervention hospitals.

In view of concerns among policymakers of the intractable differences in health outcomes between rural and metropolitan populations, ${ }^{35-37}$ our postaudit data showed equivalence between rural and urban hospitals in their adherence to the fever protocol $(\mathrm{p}=0.11)$ and was marginally so for the swallowing protocol $(\mathrm{p}=0.052)$. This is encouraging, given the likely limited staffing at rural speech pathology services, particularly after hours and at weekends. There were significant postimplementation improvements for monitoring and treatment according to the hyperglycaemia protocol in urban sites (preimplementation: $\mathrm{n}=228$ (23\%); postimplementation: $\mathrm{n}=356$
$(35 \%))$ when compared with rural sites (preimplementation: $\mathrm{n}=12 \quad(14 \%)$; postimplementation: $\mathrm{n}=7 \quad(11 \%$; $\mathrm{p}=0.0006)$ ), but further exploration of this difference was beyond the scope of our study. However, hyperglycaemia management was poorly attended in all sites regardless of location.

Our study had several limitations. First, we only had the resources to evaluate processes of care and not patient 90-day outcomes as in the original QASC trial. However, the QASC trial provided robust evidence that improvements to processes of care, even minimal ones, can dramatically result in better patient outcomes. Second, audit data were self-reported, possibly introducing selection bias as well as responder bias. However, the potential for these biases was present throughout the study and, having been obtained from a national clinical audit initiative, unlikely to be unique to our study alone. Furthermore, any biases would be expected to be consistent for the preintervention and postintervention cohorts and our primary outcome was improvement over time, rather than absolute values, further boosted by high inter-rater reliability. Despite these shortcomings, we successfully adhered to all the relevant proposed standards for the design, and conduct of a national clinical audit or quality improvement study ${ }^{31}$ invites greater confidence. Adherence to rigorous standards for quality improvement studies likely to inform clinical practice change is essential. ${ }^{38}$ To the best of our knowledge, this was the first systematic application of UK Audit Standards in a study of this type internationally. Reporting on the quality of audit should be imperative in all large-scale audits.

Collaboration with the NSF was essential for the timely completion of the study. Use of established data collection tools and existing training methods significantly reduced the cost and timeline for the study. Importantly, in future, hospitals will be able to reaudit the same processes of care easily and efficiently in the future to measure self-sustainability of improvements made. Sustainability of practice change is the next frontier in quality improvement. ${ }^{39}$ We have also provided valuable benchmarking data for other Australian states. The value of using existing data sources (ie, registries and routinely collected audit data) to measure change over time cannot be underestimated. Data linkage projects and the creation of funded, mandated national data sets with uniform and agreed data definitions are the way forward for multisite large-scale statewide or national quality improvement activities such as this.

We connected researchers with clinicians to develop a pragmatic, replicable intervention. ${ }^{13}$ The key to our success and what makes this implementation study so unique from other studies ${ }^{16}$ was the commitment from the collaborators only to use the proven implementation strategy from the QASC trial, resisting adopting the 'kitchen sink' approach, criticised elsewhere for often including untested implementation strategies. ${ }^{1}$ Involving the researchers who undertook the seminal trial was key 
to ensuring that this approach was maintained. Researchers are rarely involved in evaluation of scale-up, possibly due to the difficulty in securing dedicated funding for implementation and the need to deliver on other traditional academic key performance indicators such as publications and grant income. ${ }^{13}$ Should research impact become a metric for researcher performance, implementation research will flourish as an academic field and clinical translational initiatives such as QASCIP will increase in number and focus. Despite this, there is a role for researchers in the scale-up of interventions, ${ }^{13}$ and particular consideration could be given specifically to involving those who conducted the original research in order to promote implementation fidelity and provide advice. Dedicated funding for implementation is seriously overdue in Australia and other countries. ${ }^{13} 40$

\section{CONCLUSION}

Our study is one of the few to successfully and systematically replicate methods from a positive implementation trial. We show, for the first time, significant statewide improvements in clinical management of fever, hyperglycaemia and swallowing for patients with stroke through our clinical translational initiative conducted within a short 8-month time frame. There was, however, room for improvement in the proportion of patients receiving care according to these protocols. Protocol uptake may have been improved with a longer duration between implementation and postintervention audit. Barriers to the hyperglycaemia protocol, in particular, warrant future attention. Our results clearly demonstrate the benefits to patients of funding 'scale-up' of a proven implementation strategy across an entire statewide health system. Nonetheless, further research is recommended to illuminate the complexity of clinical evidence translation on a large scale and at pace.

\section{Author affiliations}

${ }^{1}$ Nursing Research Institute, St Vincent's Health Australia (Sydney) and Australian Catholic University, Sydney, New South Wales, Australia

${ }^{2}$ NSW Agency for Clinical Innovation, Chatswood, New South Wales, Australia

${ }^{3}$ Stroke Division, Florey Institute of Neuroscience and Mental Health, University of Melbourne, Parkville, Victoria, Australia

${ }^{4}$ School of Clinical Sciences, Monash University, Clayton, Victoria, Australia

${ }^{5}$ School of Medicine and Public Health, University of Newcastle, Newcastle, New South Wales, Australia

${ }^{6}$ National Stroke Foundation, Melbourne, Victoria, Australia

${ }^{7}$ University of Notre Dame, Broom Campus, Broome, Western Australia,

Australia

${ }^{8}$ University of Ottawa, Ottawa, Canada

${ }^{9}$ Department of Diabetes and Endocrinology, Westmead Hospital, Sydney,

New South Wales, Australia

${ }^{10}$ University of Sydney, Sydney, New South Wales, Australia

${ }^{11}$ National Centre for Epidemiology and Population Health (NCEPH), Australian National University, Canberra, Australian Capital Territory, Australia

Acknowledgements The authors would like to thank the NSW Agency for Clinical Innovation for funding to conduct this study and for in-kind support for the workshops and site visits. They would also like to thank the hospital staff for their diligence regarding data collection for the National Stroke Foundation audit. DCad was supported by a fellowship from the National
Health and Medical Research Council (NHMRC; 1063761 co-funded by National Heart Foundation). The authors would like to thank Dr Cintia Martinez-Garduno for assistance with preparing this manuscript.

Collaborators QASCIP Steering Committee, Working Group, and Audit Standards Group members: QASCIP Steering Committee members: DC, SD, James Dunne, ML, AL, SM, JW. QASCIP Working Group members: DCad, NWC, SD, Peta Drury, CD, Jeremy Grimshaw, KH, Eva Katalinic, Christopher Levi, ML, AL, SM, Elizabeth O'Brien, Sigrid Patterson, Clare Quinn, Fiona Ryan, Melissa Tinsley, Sonia Wutzke. QASCIP Audit Standards Group members: DCad, SD, Nancy Dixon, KH, AL, SM.

Contributors SM conceptualised and designed the study; obtained funding; supervised the study; participated on the Steering Committee, the Working Group, and the Audit Standards Group; assisted with delivery of the intervention; drafted the manuscript; approved the final manuscript. AL coordinated the study; assisted with delivery of the intervention; supervised data collection; drafted the manuscript; approved the final manuscript. DC chaired the Steering Committee; advised on early drafts of the manuscript; approved the final manuscript. DCad participated in the Working Group and the Audit Standard Group; advised on early drafts of the manuscript; approved the final manuscript. PM assisted with study design; conducted data analysis; assisted with drafting the manuscript; approved the final manuscript. SD assisted with study design; assisted with study supervision; participated on the Steering Committee, the Working Group, and the Audit Standards Group; assisted with delivery of the intervention; advised on early drafts of the manuscript; approved the final manuscript. $\mathrm{KH}$ assisted with data collection process; participated on the Working Group, and the Audit Standards Group; advised on early drafts of the manuscript; approved the final manuscript. ML participated in the Working Group; assisted with study co-ordination; advised on early drafts of the manuscript; approved the final manuscript. JW participated on the Steering Committee; assisted with drafting the manuscript; approved the final manuscript. NWC assisted with study design, assisted with intervention development and delivery; advised on early drafts of the manuscript; approved the final manuscript. CD assisted with study design; assisted with data analysis; assisted with drafting the manuscript; approved the final manuscript.

Funding New South Wales Agency for Clinical Innovation.

Competing interests SM received a grant from the NSW Agency for Clinical Innovation $(\mathrm{ACl})$ to undertake this work which funded $\mathrm{AL}$ as project officer. A part of these funds was also sent to the academic institutions of PM and $\mathrm{CD}$ to undertake the statistical analysis. SM is a Director on the NSW ACI Board of Directors but was appointed to this role in March 2014 after funding had been secured and all data were collected (February 2014). DC and ML are employed by NSW ACl which funded the study. DCad has a current restricted educational grant for the stroke telemedicine programme from Boehringer Ingelheim.

Ethics approval Australian Catholic University Human Ethics Committee.

Provenance and peer review Not commissioned; externally peer reviewed.

Data sharing statement No additional data are available.

Open Access This is an Open Access article distributed in accordance with the Creative Commons Attribution Non Commercial (CC BY-NC 4.0) license, which permits others to distribute, remix, adapt, build upon this work noncommercially, and license their derivative works on different terms, provided the original work is properly cited and the use is non-commercial. See: http:// creativecommons.org/licenses/by-nc/4.0/

\section{REFERENCES}

1. Grimshaw JM, Eccles MP, Lavis JN, et al. Knowledge translation of research findings. Implement Sci 2012;7:1-29.

2. Balas E, Boren S. Managing Clinical Knowledge for Health Care Improvement. In: van Bemmel JH, McCray AT, eds. Yearbook of Medical Informatics. Stuttgart: Schattauer Verlagsgesellschaft $\mathrm{mbH}$, 2000:65-70.

3. Bero LA, Grilli R, Grimshaw JM, et al. Closing the gap between research and practice: an overview of systematic reviews of interventions to promote the implementation of research findings. 
The Cochrane Effective Practice and Organization of Care Review Group. BMJ 1998;317:465-8.

4. Grimshaw JM, Shirran L, Thomas R, et al. Changing provider behavior: an overview of systematic reviews of interventions. Med Care 2001;39(8 Suppl 2):II2-45.

5. Middleton S, Alexandrov AW, Grimley R. Triage, treatment, and transfer: evidence-based clinical practice recommendations and models of nursing care for the first 72 hours of admission to hospital for acute stroke. Stroke 2015;46:e18-25.

6. Thomas LH, Watkins CL, Sutton CJ, et al. Identifying continence options after stroke (ICONS): a cluster randomised controlled feasibility trial. Trials 2014;15:509.

7. Davies P, Walker AE, Grimshaw JM. A systematic review of the use of theory in the design of guideline dissemination and implementation strategies and interpretation of the results of rigorous evaluations. Implement Sci 2010;5:14

8. Dixon-Woods M, Bosk CL, Aveling EL, et al. Explaining Michigan: developing an ex post theory of a quality improvement program. Milbank Q 2011;89:167-205.

9. Eccles M, Grimshaw J, Walker A, et al. Changing the behavior of healthcare professionals: the use of theory in promoting the uptake of research findings. J Clin Epidemiol 2005;58:107-12.

10. Milat AJ, King L, Bauman AE, et al. The concept of scalability: increasing the scale and potential adoption of health promotion interventions into policy and practice. Health Promot Int 2013:28:285-98.

11. Novak RT, Kambou JL, Diomandé FV, et al. Serogroup A meningococcal conjugate vaccination in Burkina Faso: analysis of national surveillance data. Lancet Infect Dis 2012;12:757-64.

12. The Lancet Infectious Diseases. 2018 must be the final target for polio eradication. Lancet Infect Dis 2013:13:183.

13. Milat AJ, King L, Newson R, et al. Increasing the scale and adoption of population health interventions: experiences and perspectives of policy makers, practitioners, and researchers. Health Res Policy Syst 2014;12:18.

14. Pronovost $\mathrm{P}$, Needham $\mathrm{D}$, Berenholtz $\mathrm{S}$, et al. An intervention to decrease catheter-related bloodstream infections in the ICU. N Engl $J$ Med 2006;355:2725-32.

15. Lipitz-Snyderman A, Steinwachs D, Needham DM, et al. Impact of a statewide intensive care unit quality improvement initiative on hospital mortality and length of stay: retrospective comparative analysis. BMJ 2011;342:d219.

16. Dixon-Woods M, Leslie M, Tarrant C, et al. Explaining Matching Michigan: an ethnographic study of a patient safety program. Implement Sci 2013;8:70.

17. Middleton S, McElduff $P$, Ward J, et al. Implementation of evidence-based treatment protocols to manage fever, hyperglycaemia, and swallowing dysfunction in acute stroke (QASC): a cluster randomised controlled trial. Lancet 2011;378:1699-706.

18. IST-3 Collaborative Group. Effect of thrombolysis with alteplase within $6 \mathrm{~h}$ of acute ischaemic stroke on long-term outcomes (the third International Stroke Trial [IST-3]): 18-month follow-up of a randomised controlled trial. Lancet Neurol 2013;12:768-76.

19. Stroke Unit Trialists' Collaboration. Organised inpatient (stroke unit) care for stroke. Cochrane Database Syst Rev 2013:9:CD000197.

20. Grol R, Wensing M, Eccles M. Implementation of changes in practice. Improving patient care. The implementation of change in clinical practice. Edinburgh: Elsevier, 2005:6-15.
21. Hamilton S, McLaren S, Mulhall A. Assessing organisational readiness for change: use of diagnostic analysis prior to the implementation of a multidisciplinary assessment for acute stroke care. Implement Sci 2007;2:21.

22. Grol R, Grimshaw J. Evidence-based implementation of evidence-based medicine. Jt Comm J Qual Improv 1999;25:503-13.

23. Flodgren $\mathrm{G}$, Parmelli $\mathrm{E}$, Doumit $\mathrm{G}$, et al. Local opinion leaders: effects on professional practice and health care outcomes. Cochrane Database Syst Rev 2011;(8):CD000125.

24. Drury P, Levi C, D'Este C, et al. Quality in Acute Stroke Care (QASC): process evaluation of an intervention to improve the management of fever, hyperglycemia, and swallowing dysfunction following acute stroke. Int $J$ Stroke 2014;9:766-76.

25. Ogrinc G, Mooney SE, Estrada C, et al. The SQUIRE (Standards for QUality Improvement Reporting Excellence) guidelines for quality improvement reporting: explanation and elaboration. Qual Saf Health Care 2008;17(Suppl 1):i13-32.

26. National Stroke Foundation. Acute stroke services framework Melbourne, Victoria: NSF, 2010.

27. Australian Diabetes Society. Guidelines for routine glucose control in hospital. Australia: Australian Diabetes Society, 2012.

28. National Stroke Foundation. National stroke audit-acute services clinical audit report. Melbourne, Australia, 2013.

29. National Stroke Foundation. National stroke audit acute servicesorganisational survey. National Stroke Foundation, 2013.

30. National Stroke Foundation. Acute audit. https://strokefoundation. com.au/what-we-do/treatment-programs/stroke-data-collection/ acute-audit (accessed Jun 2015)

31. Dixon N. Proposed standards for the design and conduct of a national clinical audit or quality improvement study. Int J Qual Health Care 2013;25:357-65.

32. Landis JR, Koch GG. The measurement of observer agreement for categorical data. Biometrics 1977;33:159-74.

33. Rubenstein LV, Pugh J. Strategies for promoting organizational and practice change by advancing implementation research. $J$ Gen Intern Med 2006;21(Suppl 2):S58-64.

34. Purvis T, Ritchie E, Kilkenny M, et al. National management of fever hyperglycaemia and swallow in acute stroke. Int J Stroke 2014;9 (Suppl 2):21.

35. Cadilhac DA, Purvis T, Kilkenny MF, et al. Evaluation of rural stroke services: Does implementation of coordinators and pathways improve care in rural hospitals? Stroke 2013:44:2848-53.

36. Australian Institute of Health and Welfare. Rural, regional and remote health: indicators of health system performance. Cat. no. PHE 103. Canberra: AlHW, 2008.

37. Shultis W, Graff R, Chamie C, et al. Striking rural-urban disparities observed in acute stroke care capacity and services in the Pacific Northwest: implications and recommendations. Stroke 2010;41:2278-82.

38. Berenholtz SM, Needham DM, Lubomski LH, et al. Improving the quality of quality improvement projects. Jt Comm J Qual Patient Saf 2010;36:468-73.

39. Whelan J, Love P, Pettman T, et al. Cochrane update: predicting sustainability of intervention effects in public health evidence: identifying key elements to provide guidance. J Public Health (Oxf) 2014:36:347-51.

40. Middleton S, Lyons N. Stroke care in Australia: Why is it still the poor cousin of health care? Med J Aust 2013;199:166. 